\title{
Studies on the Biosynthesis of Bialaphos. Biochemical Mechanism of C-P Bond Formation : \\ Discovery of Phosphonopyruvate Decarboxylase which Catalyzes the Formation of Phosphonoacetaldehyde from Phosphonopyruvate ${ }^{\dagger}$
}

\author{
Hideo Nakashita $^{\dagger \dagger}$, Kei Watanabe, Osamu Hara ${ }^{\text {a }}$, Tomomi Hidaka \\ and HaRuo SeTo* \\ Institute of Molecular and Cellular Biosciences, The University of Tokyo, \\ Bunkyo-ku, Tokyo 113, Japan \\ ${ }^{a}$ Pharmaceutical Research Center, Meiji Seika Kaisha Ltd., \\ Morooka-cho, Kohoku-ku, Yokohama 222, Japan
}

(Received for publication October 2, 1996)

\begin{abstract}
The biosynthetic step following the phosphoenolpyruvate (PEP) phosphomutase reaction which forms a $\mathrm{C}-\mathrm{P}$ bond of bialaphos was proven by the identification of phosphonopyruvate (PnPy) and phosphonoacetaldehyde (PnAA) as intermediates in the culture broth of Streptomyces hygroscopicus, a producing organism of bialaphos, and by detection of enzymatic decarboxylation of PnPy to PnAA. Purified PnPy decarboxylase turned out to require thiamine diphosphate and $\mathrm{Mg}^{2+}$ as cofactors. PnPy decarboxylase drives the unfavorable forward reaction to form PnPy catalyzed by PEP phosphomutase and is suggested to be essential to $\mathrm{C}-\mathrm{P}$ compound biosynthesis.
\end{abstract}

Among vast number of secondary metabolites, bialaphos (BA), a product of Streptomyces hygroscopicus SF-1293 with a herbicidal activity ${ }^{1,2)}$ is characterized as a tripeptide possessing a unique $\mathrm{C}-\mathrm{P}-\mathrm{C}$ bond. Through the extensive studies in the past several years, we have revealed that the biosynthetic pathway of BA consists of more than 13 steps $^{3 \sim 15)}$. Among them, the first $\mathrm{C}-\mathrm{P}$ bond forming reaction has turned out to be seemingly common to the biosyntheses of all the C-P compounds.

Since the discovery of the first natural C-P compound, 2-aminoethylphosphonic acid (AEP) ${ }^{16)}$, the biosynthetic mechanism of the C-P bond formation has attracted considerable interest, and the enzyme phosphoenolpyruvate phosphomutase (PEP phosphomutase) catalyzing the formation of phosphonopyruvate (PnPy) from phosphoenolpyruvate (PEP) (Fig. 1) has been purified and identified from several organisms $\mathrm{s}^{6,17 \sim 19)}$. This enzyme had remained as a big mystery for more than three decades, since no one succeeded in detecting its activity even in cell free systems.

However, our recent finding that the equilibrium of the $\mathrm{C}-\mathrm{P}$ bond formation reaction favors strongly the formation of phosphate ester, i.e. cleavage of the $\mathbf{C}-\mathbf{P}$ bond to give phosphoenolpyruvate ${ }^{17,18,20)}$ enabled purification of the enzyme by observing this reverse reaction. This characteristic feature of PEP phosphomutase im- plied that a mechanism to convert effectively PnPy to the next intermediate would be essential to produce C-P compounds.

The next step following the PEP phosphomutase reaction, which is considered to be decarboxylation of PnPy to generate phosphonoacetaldehyde (PnAA) (Fig. 1), has recently been the focus of our research interest. The first identification of PnPy had been as a product of bioconversion from PEP using the cell free extract of Tetrahymena pyriformis which produced $\mathrm{AEP}^{21)}$. Recently PnPy was confirmed to be the substrate of PEP phosphomutase ${ }^{4,19)}$. However, PnAA and even PnPy were still proposed intermediates to be identified as natural compounds, and the reactions including these compounds following PEP phosphomutase reaction were still unclear. We have attempted to investigate the decarboxylation of PnPy (step 2 reaction) to make clear the mechanism of $\mathrm{C}-\mathrm{P}$ bond formation.

In the course of our study, various kinds of BA nonproducing blocked mutants of $S$. hygroscopicus had been identified and characterized ${ }^{5 \sim 8,11,12}$. One of these blocked mutants, S. hygroscopicus E26, is defective in PEP phosphomutase and does not produce any $\mathrm{C}-\mathrm{P}$ compounds ${ }^{4}$. Another BA non-producing mutant, S. hygroscopicus NP46, accumulates hydroxyethylphosphonic acid (HEP) in the culture broth ${ }^{22)}$, probably because it is

$\dagger$ For the last paper of this series, see ref. 9.

$\dagger^{\dagger}$ Present address: The Institute of Physical and Chemical Research (RIKEN), Hirosawa, Wako-shi, Saitama 351-01, Japan. 
Fig. 1. Proposed biosynthetic pathway of bialaphos.

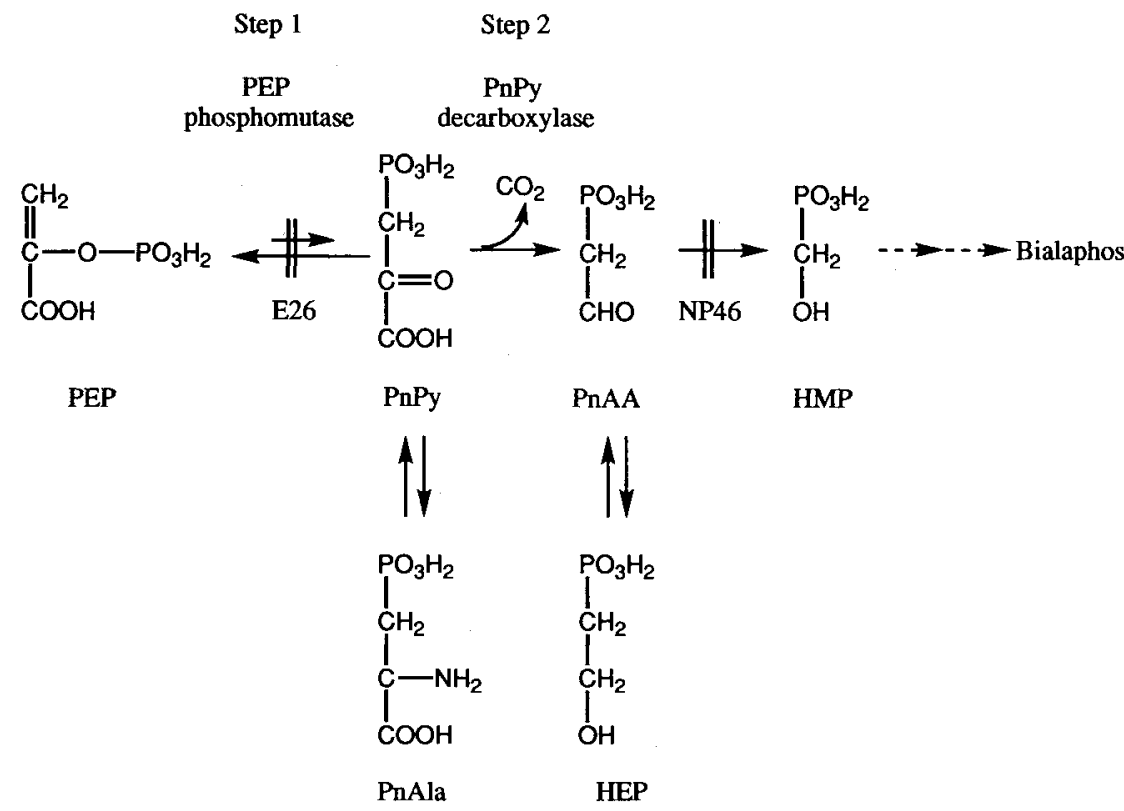

PEP, phosphoenolpyruvate; PnPy, phosphonopyruvate; PnAA, phosphonoacetaldehyde; HEP, hydroxyethylphosphonic acid; HMP, hydroxymethylphosphonic acid.

defective in the reaction following PnAA generation (Fig. 1). In addition, several $\mathrm{C}-\mathrm{P}$ compound-producing microorganisms were used in our study in order to facilitate to analyze the step 2 reaction in detail by exploiting their characteristic biochemical features. Pseudomonas gladioli B-1 was identified as an HEP producing strain, and PEP phosphomutase was purified from this strain ${ }^{18)}$. Streptomyces wedmorensis 144-91 is a high-producer of fosfomycin and its mutant NP-7 was suggested to be a step 2 deficient mutant by bio-conversion experiment ${ }^{23)}$. Pseudomonas viridiflava, identified as a fosfomycin and fosfadecin producing strain ${ }^{24)}$, was also utilized in this experiment.

Here we report the determination of the mechanism of step 2 by identification of proposed intermediates, PnPy and PnAA, in the culture broth and by discovery of the enzymatic activity of PnPy decarboxylase which catalyzes the conversion of PnPy to PnAA. We also describe the purification and partial characterization of PnPy decarboxylase.

\section{Materials and Methods}

\section{Materials}

DEAE-cellulose DE52 was purchased from Whatman Ltd., and Mono Q HR 5/5 and PD-10 were obtained from Pharmacia LKB Biotechnology. TSK-gel Phenyl5PW and TSK-gel G4000SW were purchased from Toso
Co. SDS-polyacrylamide gradient gel was purchased from Daiichi Pure Chemical Co., Ltd.

HPLC was performed by using an 800 series HPLC system (Japan Spectroscopic Co., Ltd.).

PnPy was prepared by non-enzymatic transamination $^{25)}$ from phosphonoalanine (PnAla), a product of Sigma Chemical Co. PnAA was prepared as described by ISBEL ${ }^{26)}$.

All other chemicals without specification were of reagent grade and were purchased from Nacalai Tesque Inc.

\section{Bacterial Strains and Growth Conditions}

S. hygroscopicus E26, NP46 and Streptomyces wedmorensis 144-91 and NP-7 were obtained from the Meiji Seika Kaisha Culture Collection. Pseudomonas viridiflava was obtained from Takeda Chemical Industries, Ltd.

Cultures of Streptomycetes were routinely stored at $-20{ }^{\circ} \mathrm{C}$ in $30 \%$ glycerated S- 1 medium consisting of $2 \%$ soluble starch, $1 \%$ polypeptone, $0.3 \%$ meat extract and $0.05 \% \mathrm{~K}_{2} \mathrm{HPO}_{4}$. Cells from frozen culture $(0.4 \mathrm{ml})$ were inoculated into a tube containing $10 \mathrm{ml}$ of $\mathrm{S}-1$ medium and cultured at $27^{\circ} \mathrm{C}$ for 2 days with shaking. This seed culture $(1.2 \mathrm{ml})$ was inoculated into the $60 \mathrm{ml} \mathrm{BA}$ production medium contained in a 500-ml Erlenmeyer flask and incubated at $27^{\circ} \mathrm{C}$ for 4 or 5 days with shaking. BA production medium contained $7 \%$ glucose, $3.9 \%$ wheat germ, $2.5 \%$ sun grain (Sungross; Suntory Ltd.), $0.1 \%$ $\mathrm{KH}_{2} \mathrm{PO}_{4}, 0.0001 \% \mathrm{CoCl}_{2}$ and silicon KM- 72 antifoam (Shin-etsu Chemical Co.), and $\mathrm{pH}$ was adjusted to 7.0. 
${ }^{31} \mathrm{P}$ NMR Analysis of Broth Filtrates

Broth filtrates were concentrated 10 times and analyzed by a JEOL GSX500 NMR spectrometer operating at $202.35 \mathrm{MHz}$ at $25^{\circ} \mathrm{C} .{ }^{31} \mathrm{P}$-Chemical shift values are reported relative to external $85 \% \mathrm{H}_{3} \mathrm{PO}_{4}$.

For dinitrophenylhydrazine (DNP) modification experiments, broth filtrate $(30 \mathrm{ml})$ was mixed with $3 \mathrm{ml}$ of $0.5 \% \mathrm{DNP}$ in $2 \mathrm{~N} \mathrm{HCl}$ and stored at $4^{\circ} \mathrm{C}$ for 30 minutes. The reaction mixture was extracted with ethyl acetate, concentrated in vacuo, and then the residue was dissolved in ethyl acetate for ${ }^{31} \mathrm{P}$ NMR analysis.

\section{Enzyme Assay}

The reaction mixture ( $2 \mathrm{ml}$ ) consisting of $0.5 \mathrm{mM} \mathrm{PnPy}$, $1 \mathrm{~mm}$ thiamine diphosphate and $5 \mathrm{~mm} \mathrm{MgSO}_{4}$ in the cell free extracts was incubated at $30^{\circ} \mathrm{C}$ with shaking and the reaction was terminated by addition of $250 \mu \mathrm{l}$ of $0.5 \%$ DNP in $2 \mathrm{~N} \mathrm{HCl}$. The DNP modified reaction products were extracted with ethyl acetate and dried with $\mathrm{N}_{2}$ gas. This sample was dissolved in $100 \mu 1$ of $10 \%$ acetonitrile in $4 \%$ phosphoric acid and applied to HPLC analysis using a TSK-gel ODS 80 column $(7.6 \times 250 \mathrm{~mm}$, Toso Co.). After washing with $10 \%$ acetonitrile in $4 \%$ phosphoric acid for 5 minutes, the elution was carried out at a flow rate of $0.6 \mathrm{ml} /$ minute with a linear gradient of 30 to $35 \%$ acetonitrile in $4 \%$ phosphoric acid in 30 minutes. DNP modified compounds were detected by the absorbance at $365 \mathrm{~nm}$.

\section{Preparation of Cell Free Extract}

Mycelia of S. hygroscopicus mutants, $S$. wedmorensis and cells of $P$. viridiflava were harvested by centrifugation $\left(3,000 \times g, 15\right.$ minutes, $\left.4^{\circ} \mathrm{C}\right)$ and were suspended in 3 -fold volumes of $50 \mathrm{~mm}$ Tris- $\mathrm{HCl}$ buffer ( $\mathrm{pH} 7.5$ ) after washing twice with the same buffer. The suspension was subjected to ultrasonic treatment for 10 minutes $(2 \mathrm{~N}-100$; Toyo Rikoh Co.) Cell debris was removed by centrifugation at $14,000 \times g$ and $4^{\circ} \mathrm{C}$ for 15 minutes.

\section{Purification}

The cell free extract was prepared as above from $100 \mathrm{~g}$ cell paste, which was harvested from $480 \mathrm{ml}$ culture broth. All subsequent steps were performed at $4^{\circ} \mathrm{C}$. Protein concentration was determined by using Protein Assay (Bio-Rad). The cell free extract $(300 \mathrm{ml})$ was brought to $30 \%$ saturation by addition of solid ammonium sulfate over 30 minutes, stirred for an additional 30 minutes, and centrifuged $(14,000 \times g, 15$ minutes). The supernatant was collected and adjusted to $60 \%$ saturation by addition of solid ammonium sulfate over 30 minutes, stirred for an additional 30 minutes, and centrifuged. The resulting pellet was dissolved in $2,000 \mathrm{ml}$ of $50 \mathrm{~mm}$ Tris- $\mathrm{HCl}$ buffer (pH 7.5) and was loaded on a DEAE cellulose column (60 by $300 \mathrm{~mm}$ ) previously equilibrated with the same buffer. After washing with the same buffer, the column was eluted with a linear gradient from 0 to $0.3 \mathrm{M} \mathrm{NaCl}$ in the same buffer in a volume of $1,400 \mathrm{ml}$. Fractions of $10 \mathrm{ml}$ each were collected. PnPy decarboxylase was eluted at around $0.05 \mathrm{M} \mathrm{NaCl}$ concentration.

The active fractions eluted at 0.05 to $0.08 \mathrm{M} \mathrm{NaCl}$ were combined and precipitated by addition of solid ammonium sulfate to $60 \%$ saturation. After centrifugation, the pellet was dissolved in sodium phosphate buffer (50 mM, pH 7.0) containing $1.2 \mathrm{M}$ ammonium sulfate. The sample was loaded on a hydrophobic interaction column, TSK-gel Phenyl-5PW ( 21.5 by $150 \mathrm{~mm}$ ), previously equilibrated with the same buffer, running on an HPLC system at a flow rate of $3 \mathrm{ml} /$ minute. The elution was carried out with a linear gradient from 0.72 to $0 \mathrm{M}$ ammonium sulfate in sodium phosphate buffer $(50 \mathrm{~mm}$, $\mathrm{pH}$ 7.0) after washing with $0.72 \mathrm{M}$ ammonium sulfate in the same buffer. PnPy decarboxylase was eluted at an ammonium sulfate concentration of around $0.65 \mathrm{M}$.

The active fractions were pooled and concentrated by ultrafiltration using Centricon (Amicon) and applied to gel filtration by an HPLC system using a TSK-gel G3000SW column. The gel filtration was performed with sodium phosphate buffer $(10 \mathrm{~mm}, \mathrm{pH} 7.0)$ containing $0.1 \mathrm{M} \mathrm{NaCl}$ and $10 \%$ glycerol at a flow rate of $0.4 \mathrm{ml} /$ minute. Fractions of $0.8 \mathrm{ml}$ each were collected.

The pooled enzyme solution was finally loaded at a flow rate of $1.0 \mathrm{ml} /$ minute on a Mono Q HR $5 / 5$ column equilibrated with $50 \mathrm{~mm}$ Tris- $\mathrm{HCl}$ buffer $(\mathrm{pH}$ 7.5). The elution was carried out with a linear gradient from 0 to $0.15 \mathrm{M} \mathrm{NaCl}$ in the same buffer, and each peak was collected separately by monitoring the absorbance at $280 \mathrm{~nm}$. Purified PnPy decarboxylase was eluted at around $0.05 \mathrm{M} \mathrm{NaCl}$.

\section{PEP Phosphomutase Coupling Reaction}

The reaction mixture $(2 \mathrm{ml})$ contained $1.5 \mathrm{~mm}$ thiamine diphosphate, $5 \mathrm{mM} \mathrm{Mg}^{2+}, 50 \mu \mathrm{l}$ of PnPy decarboxylase preparation ( $0.1 \mathrm{mg}$ protein), and various concentrations of PEP and PEP phosphomutase in $50 \mathrm{~mm}$ Tris- $\mathrm{HCl}$ buffer ( $\mathrm{pH}$ 7.5). PEP phosphomutase $(60 \mathrm{ng} / \mu \mathrm{l})$ was purified from P. gladioli B-1, and PnPy decarboxylase was partially purified from $S$. hygroscopicus E26 by ammonium sulfate precipitation $(30 \sim 60 \%)$. The concentrations of PEP were $1,10,50$ and $100 \mathrm{mM}$. The concentration of PEP phosphomutase was increased to $150 \mathrm{ng} / \mathrm{ml}$ when the PEP concentration was $50 \mathrm{~mm}$. The reaction was initiated by addition of PnPy decarboxylase. The reaction mixture was incubated at $30^{\circ} \mathrm{C}$ for 7 hours with shaking and terminated by DNP treatment under acidic condition. DNP derivatives were extracted with ethyl acetate and evaporated, and the residues were subjected to HPLC analysis.

\section{Results}

\section{Determination of the Step 2 Reaction}

${ }^{31} \mathrm{P}$ NMR spectroscopy is a very suitable method for detecting selectively $\mathrm{C}-\mathrm{P}$ compounds from the other phosphorous compounds even in crude samples, although the detection sensitivity is not so high ${ }^{27)}$. Thus an attempt 
was made to detect C-P compounds accumulated in the culture broths of various mutants of $S$. hygroscopicus using ${ }^{31} \mathrm{P}$ NMR. This experiment proved the accumulation of several C-P compounds such as AEP, hydroxymethylphosphonic acid (HMP), HEP ${ }^{22)}$ and phosphonoalanine (PnAla) which had been isolated from several blocked mutants of the BA producer ${ }^{11)}$, but PnPy and PnAA were not seen, presumably due to their instability or their low concentrations in the culture broth. Both PnPy and PnAA are considerably unstable, while the $\mathrm{C}-\mathrm{P}$ bonds of other $\mathrm{C}-\mathrm{P}$ compounds are very stable. PnPy easily decomposed to pyruvic acid and phosphoric acid, and PnAA to acetaldehyde and phosphoric acid. Since only PnPy and PnAA with a carbonyl group were assumed to be involved in the early stage of the C-P compounds biosynthesis, we tried to detect them after modification with dinitrophenylhydrazine (DNP). ${ }^{31} \mathrm{P}$ NMR analysis of a DNP-treated broth filtrate of NP46, a blocked mutant of $S$. hygroscopicus accumulating HEP in the culture broth $^{24)}$, showed distinct signals of PnPy and PnAA derivatives at 21.5 and $19.5 \mathrm{ppm}$, respectively (Fig. 2). The signals of PnPy and PnAA were not seen in the mutant E-26 defective in step 1. These

Fig. 2. ${ }^{31} \mathrm{P}$ NMR spectrum of DNP-treated broth filtrate of S. hygroscopicus NP46.

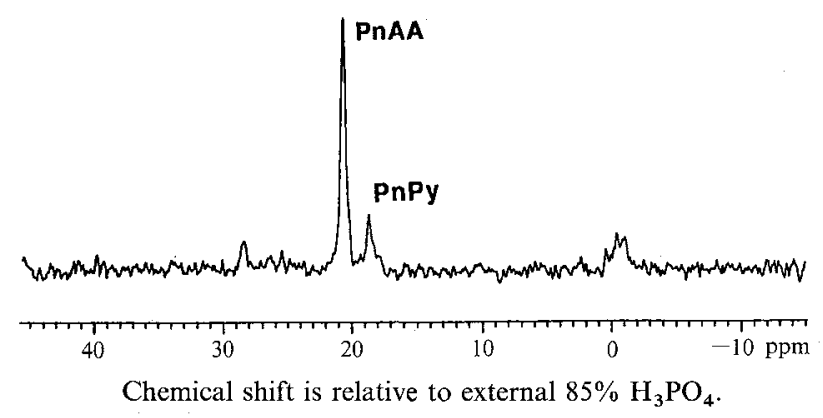

Table 1. Conversion of C-P compounds to bialaphos by mutant strains of $S$. hygroscopicus.

\begin{tabular}{ccc}
\hline \multirow{2}{*}{ C-P compound* } & \multicolumn{2}{c}{ Bialaphos production $(\mu \mathrm{g} / \mathrm{ml})$} \\
\cline { 2 - 3 } & E26 & NP46 \\
\hline PnPy & 3.0 & - \\
PnAla & 13.0 & - \\
PnAA & 0.2 & - \\
AEP & 2.5 & - \\
HMP & 5.5 & 15.0 \\
\hline
\end{tabular}

Bialaphos production was measured by antimicrobial activity against Bacillus subtilis.

* Concentration of substrate; $100 \mu \mathrm{g} / \mathrm{ml}$. results indicated that PnPy and PnAA were produced by $S$. hygroscopicus in the early stage of the BA biosynthesis.

Conversion experiments of PnPy, PnAA and other C-P compounds with washed cells of several BA nonproducing mutants were performed as previously report$\mathrm{ed}^{11)}$. The results showed that PnPy, PnAla (a biological equivalent of PnPy) and PnAA were converted to BA by the strain E26 but neither were converted by NP46 (Table 1). On the other hand the next intermediate, HMP was converted to BA by both strains of E26 and NP46. From the results of these conversion experiments using washed cells as well as their presence in the broth filtrate, PnPy and PnAA were confirmed as biosynthetic intermediates of BA.

\section{PnPy Decarboxylase Activity}

In order to analyze the step 2 pathway from PnPy to PnAA in detail, the enzymatic activity of step 2 was examined with the cell free extract of NP46. Conversion of PnPy to PnAA was detected by a reverse phased HPLC analysis system after the produced PnAA was treated with DNP. The retention times of PnPy-DNP and PnAA-DNP in this assay were 21.5 and 25.5 minutes, respectively. By this method PnAA-DNP was detected in the reaction mixture using the NP-46 cell-free extract only when incubation was done for 4 to 6 hours (Fig. 3), despite the unfavorable presence in the reaction mixture of PEP phosphomutase which should disturb the enzyme

Fig. 3. HPLC chromatogram of PnPy decarboxylase assay.

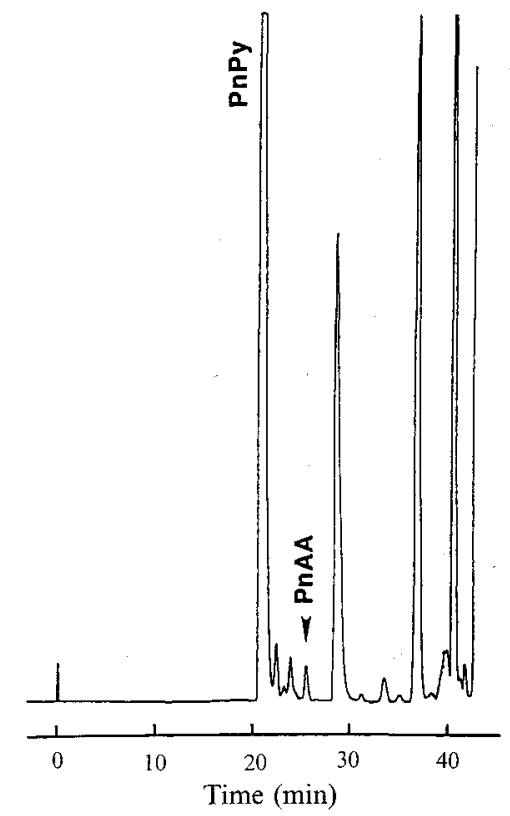

The enzymatic reaction and sample preparation for HPLC were performed as described in materials and methods, and $50 \mu 1$ of the sample was analyzed by HPLC. 
assay by consuming PnPy. PnAA seemed to be gradually decomposed or converted to other compounds after being produced from PnPy. When a heated cell free extract was used for this assay, PnAA-DNP was not produced. Therefore, this assay system enabled us to detect the activity of the novel enzyme, PnPy decarboxylase. The enzymatic activity was also detected in the cell free extract of the mutant E-26 lacking the PEP phosphomutase activity.

These results indicated that step 2 reaction of the BA biosynthesis following the PEP phosphomutase reaction is the decarboxylation of PnPy to generate PnAA catalyzed by PnPy decarboxylase. Thus the first two steps of the BA biosynthesis were identified definitely.

\section{Purification of PnPy Decarboxylase}

To purify PnPy decarboxylase, S. hygroscopicus E26 lacking PEP phosphomutase activity was utilized as an enzyme source, because the presence of PEP phosphomutase disturbed the detection of the enzymatic activity of the decarboxylase during purification. The specific activity of this enzyme could not be accurately estimated by the assay method described in Materials and Methods due to the gradual decomposition of PnAA during the reaction. From the cell free extract containing $2,187 \mathrm{mg}$ protein PnPy decarboxylase was purified to homogeneity ( $c a .0 .36 \mathrm{mg}$ ) by a five-step protocol as described in Materials and Methods.

\section{Properties of PnPy Decarboxylase}

The molecular weight of the PnPy decarboxylase was estimated as $135 \mathrm{kDa}$ by gel filtration using TSK-gel G3000SW and its subunit was estimated as $36 \mathrm{kDa}$ by SDS-PAGE. This enzyme was stable for 3 weeks during storage in $50 \mathrm{~mm}$ Tris- $\mathrm{HCl}$ buffer $\left(\mathrm{pH} \mathrm{7.5)}\right.$ at $4^{\circ} \mathrm{C}$. Pyruvate decarboxylase catalyzing the similar reaction requires thiamine diphosphate (TPP) and $\mathrm{Mg}^{2+}$ as cofactors. Requirement of these cofactors for the activity was examined with an enzyme preparation partially purified by ammonium sulfate fractionation $(30 \sim 60 \%)$ followed by desalting by PD-10 column chromatography. The PnPy decarboxylase activity was detected in the reaction mixture containing both TPP and $\mathrm{Mg}^{2+}$ but not in those lacking either or both of TPP and $\mathrm{Mg}^{2+}$, indicating that PnPy decarboxylase required TPP and $\mathrm{Mg}^{2+}$ as cofactors. Pyruvate decarboxylase ${ }^{28,29)}$ also catalyzes $\alpha$-keto acid decarboxylation and requires TPP as a cofactor. Pyruvate decarboxylase, however, could not utilize PnPy as a substrate for decarboxylation (data not shown).
Table 2. Generation of PnAA via PnPy from PEP by PEP phosphomutase and PnPy decarboxylase ${ }^{a}$ coupling system.

\begin{tabular}{cccc}
\hline PEP $(\mathrm{mM})$ & PEP phosphomutase $(\mathrm{ng})$ & $\mathrm{PnPy}(\mu \mathrm{M})$ & $\mathrm{PnAA}(\mu \mathrm{M})$ \\
\hline 1 & 180 & $\mathrm{ND}^{\mathrm{b}}$ & $\mathrm{ND}^{\mathrm{b}}$ \\
10 & 180 & 36 & 27 \\
50 & 0 & 0 & 0 \\
50 & 180 & 81 & 25 \\
50 & 300 & 133 & 51 \\
100 & 180 & 171 & 24 \\
\hline
\end{tabular}

a PnPy decarboxylase was prepared from the cell free extract of $S$. hygroscopicus E26 by ammonium sulfate precipitation $(30 \sim 60 \%)$.

b The peaks of these compounds were too faint to estimate.

Synthesis of PnAA by Biological System

In order to confirm the $\mathrm{C}-\mathrm{P}$ bond formation pathway from step 1 to step 2, a PEP phosphomutase-PnPy decarboxylase coupled system was tested for the production of PnAA from PEP. PnPy decarboxylase was prepared from $S$. hygroscopicus E26 to avoid contamination of PEP phosphomutase activity. PEP phosphomutase purified from $P$. gladioli $\mathrm{B}-1$ was used for this system, because PEP phosphomutase of $S$. hygroscopicus was too unstable to be purified enough to avoid the contamination of PnPy decarboxylase. Since the ratio of the substrate (PEP) to the product (PnPy) was reported to be over 500:1 at the equilibrium of the PEP phosphomutase reaction, a large excess amount of the substrate PEP up to $100 \mathrm{~mm}$ was used in this reaction. Neither PnPy nor PnAA were produced from PEP at the concentration of $50 \mathrm{~mm}$ in the presence of only PnPy decarboxylase (Table 2). By addition of P. gladioli B-1 PEP phosphomutase into the reaction mixture, $\mathrm{PnAA}$ was produced from $\mathrm{PEP}$ via PnPy by this coupled system even when the concentration of PEP was as low as $10 \mathrm{~mm}$. This suggested that both enzymes functioned in C-P compound biosynthesis and that step 2 reaction converted PnPy to PnAA, driving the step 1 reaction in the forward direction.

\section{PnPy Decarboxylase Activity of Other C--P Compound Producing Strains}

In the reaction mixture containing the cell free extract of a fosfomycin producing strain, S. wedmorensis 144-91, most of the substrate PnPy was converted to PnAA (Fig. 4A), indicating that this strain possesses strong $\mathrm{PnPy}$ decarboxylase activity. On the other hand PnAA was not 
Fig. 4. PnPy decarboxylase activities of other C-P compound producing strains.

A

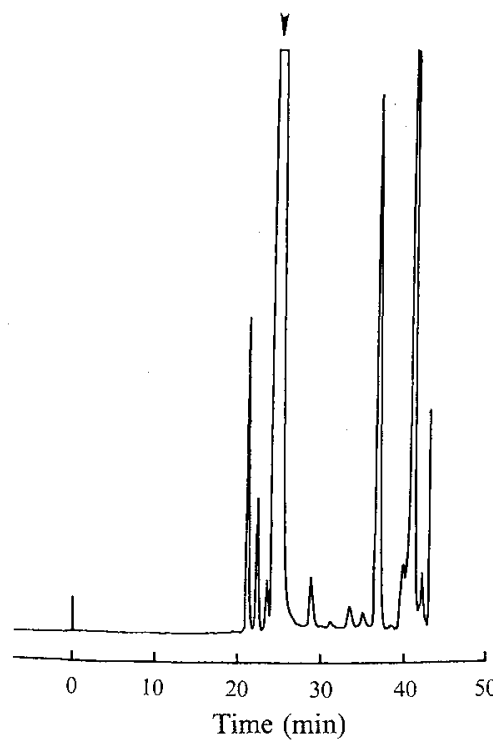

B

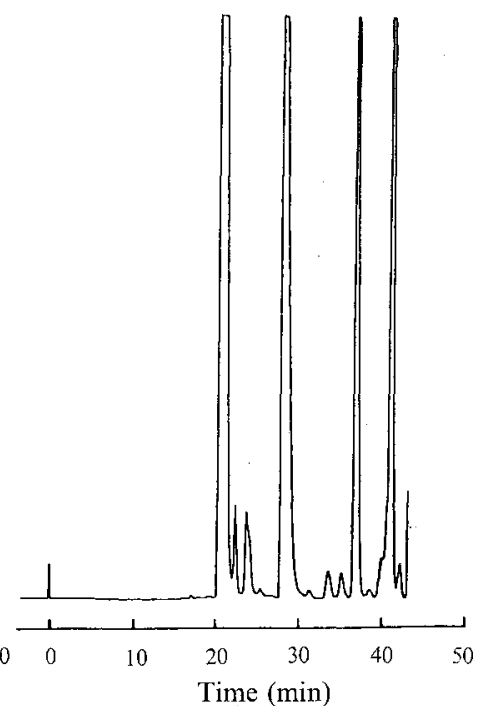

C

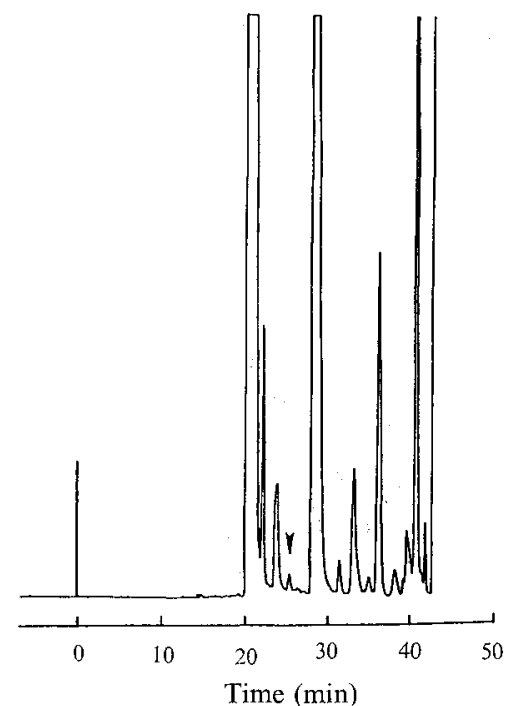

Arrowheads indicate the peaks of PnAA-DNP.

A, Fosfomycin producing strain $S$. wedmorensis 144-91; B, step 2 deficient mutant S. wedmorensis NP-7; C, fosfadecin producing strain Pseudomonas viridiflava.

detected in the reaction mixture using the cell free extract of $S$. wedmorensis NP-7 (Fig. 4B), supporting biochemically that NP-7 is a step 2 deficient mutant. PnAA was also detected when the cell free extract of $P$. viridiflava was used in the reaction mixture (Fig. 4C), indicating the existence of PnPy decarboxylase in a Gram-negative bacterium producing a C-P compound, fosfadecin. These indicated that the step 2 reaction is common to all of C-P compound biosyntheses and catalyzed by PnPy decarboxylase.

\section{Discussion}

PnPy and PnAA were confirmed as biosynthetic intermediates for BA by the work reported herein. The discovery of PnPy decarboxylase as well as the coupling system consisting of PEP phosphomutase and PnPy decarboxylase indicated that step 2 reaction is common to the biosyntheses of all C-P compounds. This was also supported by the detection of PnPy decarboxylase activities in $S$. wedmorensis and $P$. viridiflava which produce fosfomycin and fosfadecin, respectively.

The non-oxidative $\alpha$-keto acid decarboxylation of PnPy is analogous to the pyruvate decarboxylase reaction and needs TPP and $\mathrm{Mg}^{2+}$ as cofactors. Pyruvate decarboxylase, however, did not utilize PnPy as a substrate despite its wide substrate specificity, excluding the possibility that the enzyme plays a role in the biosynthesis of BA. Thus PnPy decarboxylase is concluded to be the specific enzyme catalyzing the conversion of PnPy to PnAA in BA biosynthesis.
This study showed that PnAA was produced from PEP by the coupled system of PEP phosphomutase and PnPy decarboxylase. Although the accurate conversion ratio could not be estimated due to gradual decomposition of PnAA during the reaction, step 2 reaction proved to drive the equilibrium of the step 1 reaction, which otherwise favored the formation of PEP, in the forward direction in $\mathrm{C}-\mathrm{P}$ compound biosynthesis.

In living systems PnPy may well be converted to PnAla which is subjected to several different metabolisms. Our studies, however, suggest that most $\mathrm{C}-\mathrm{P}$ compounds are synthesized through PnPy and PnAA, and that PnPy decarboxylase is essential to $\mathrm{C}-\mathrm{P}$ compound biosynthesis. PnAA is converted to 2-hydroxypropylphosphonic acid in fosfomycin biosynthesis ${ }^{30)}$ and is believed to be converted to HMP in BA biosynthesis ${ }^{22}$. PnAA is located at the pivotal point from where biosynthetic pathways diversify to form various $\mathrm{C}-\mathrm{P}$ compounds and the next reactions following PnPy decarboxylation would stabilize the C-P bonds: Thus PnPy decarboxylase is critical for the structural diversity of $\mathrm{C}-\mathrm{P}$ compounds as well as for the $\mathrm{C}-\mathrm{P}$ bond formation in the $\mathrm{C}-\mathrm{P}$ compound biosyntheses. Further studies on the reaction mechanism and the enzymatic properties of this enzyme are necessary to investigate the significance of C-P compound metabolism in living system.

\section{References}

1) Kondo, Y.; T. Shomura, Y. Ogawa, T. Tsuruoka, H. Watanabe, K. Totsukawa, T. Suzuki, C. Moriyama, J. Yoshida, S. Inouye \& T. NiIDa: Studies on a new antibiotic SF-1293. I. Isolation and physico-chemical and 
biological characterization of SF-1293 substance. Sci. Reports of Meiji Seika Kaisha 13: $34 \sim 41,1973$

2) Ogawa, Y.; T. Tsuruoka, S. InOuYe \& T. Nimd: Studies on a new antibiotic SF-1293. II. Chemical structure of antibiotic SF-1293. Sci. Reports of Meiji Seika Kaisha 13: $42 \sim 48,1973$

3) Seto, H.; T. Sasaki, S. Imai, T. Tsuruoka, H. Ogawa, A. Satoh, S. InOuye, T. NiIDA \& N. OTAKE: Studies on the biosynthesis of bialaphos (SF-1293). 2. Isolation of the first natural products with a C-P-H bond and their involvement in the C-P-C bond formation. J. Antibiotics 36: $96 \sim 98,1983$

4) Hidaka, T.; M. Mori, S. Imai, O. Hara, K. Nagaoka \& H. Seto: Studies on the biosynthesis of bialaphos (SF-1293). 9. Biochemical mechanism of C-P bond formation in bialaphos: discovery of phosphoenolpyruvate phosphomutase which catalyzes the formation of phosphonopyruvate from phosphoenolpyruvate. J. Antibiotics 42: $491 \sim 494,1989$

5) Hidaka, T.; H. Seto \& S. ImaI: Biosynthetic mechanism of C-P bond formation; Isolation of carboxyphosphonoenolpyruvate and its conversion to phosphinopyruvate. J. Am. Chem. Soc. 111: 8012 8013, 1989

6) Hidaka, T.; S. Imai, O. Hara, H. Anzai, T. Murakami, K. NAGaOKa \& H. SETo: Carboxyphosphonoenolpyruvate phosphonomutase, a novel enzyme catalyzing C-P bond formation. J. Bacteriol. 172: 3066 3072, 1990

7) Imai, S.; H. Seto, T. Sasaki, T. Tsuruoka, H. Ogawa, A. Satoh, S. Inouye, T. NiIda \& N. Otake: Studies on the biosynthesis of bialaphos (SF-1293). 6. Production of $\mathrm{N}$-acetyldemethylphosphinothricin and $\mathrm{N}$-acetylbialaphos by blocked mutants of Streptomyces hygroscopicus SF-1293 and their roles in the biosynthesis of bialaphos. J. Antibiotics 38: $687 \sim 690,1985$

8) Kamigiri, K.; T. Hidaka, S. Imai, T. Murakami \& H. SETO: Studies on the biosynthesis of bialaphos (SF-1293). 12. C-P bond formation mechanism of bialaphos: discovery of a P-methylation enzyme. J. Antibiotics 45: $781 \sim 787,1992$

9) Lee, S.-H.; T. Hidaka, H. Nakashita \& H. Seto: Carboxyphosphonoenolpyruvate synthase-encoding gene from the bialaphos-producing organism Streptomyces hygroscopicus. Gene 153: 143 144, 1995

10) Seto, H.; S. Imai, T. Tsuruoka, A. Satoh, M. Kojima, S. InOuYe, T. SASAKI \& N. Otake: Studies on the biosynthesis of bialaphos (SF-1293). 1. Incorporation of ${ }^{13} \mathrm{C}$ - and ${ }^{2} \mathrm{H}$-labeled precursors into bialaphos. $\mathbf{J}$. Antibiotics 35: 1719 1721, 1982

11) Seto, H.; S. Imai, T. Tsuruoka, H. Ogawa, A. Satoh, T. SASAKI \& N. OTAKE: Studies on the biosynthesis of bialaphos (SF-1293). Part 3. Production of phosphinic acid derivatives, MP-103, MP-104 and MP-105, by a blocked mutant of Streptomyces hygroscopicus SF-1293 and their roles in the biosynthesis of bialaphos. Biochem. Biophys. Res. Comm. 111: 1008 1014, 1983

12) Seto, H.; S. Imai, T. Sasaki, K. Shimotohno, T. Tsuruoka, H. Ogawa, A. Satoh, S. Inouye, T. Nima $\&$ N. Otake: Studies on the biosynthesis of bialaphos (SF-1293). 5. Production of 2-phosphinomethylmalic acid, an analogue of citric acid by Streptomyces hygroscopicus SF-1293 and its involvement in the biosynthesis of bialaphos. J. Antibiotics 37: 1509 1511, 1984
13) Shimotohno, K.; H. Seto, N. Otake, S. Imai \& A. Satoh: Studies on the biosynthesis of bialaphos (SF-1293). 7. The absolute configuration of 2-phosphinomethylmalic acid, a biosynthetic intermediate of bialaphos. J. Antibiotics 39: $1356 \sim 1359,1986$

14) Shimotohno, K.; H. Seto, N. Otake, S. Imai \& T. MuraKami: Studies on the biosynthesis of bialaphos (SF-1293). 8. Purification and characterization of 2-phosphinomethylmalic acid synthase from Streptomyces hygroscopicus SF-1293. J. Antibiotics 41: 1057 1065,1988

15) Shimotohno, K. W.; S. Imai, T. Murakami \& H. Seto: Purification and characterization of citrate synthase from Streptomyces hygroscopicus SF-1293 and comparison of its properties with those of 2-phosphinomethylmalic acid synthase. Agric. Biol. Chem. 54: 463 470, 1990

16) Horiguchi, M. \& M. Kandatsu: Isolation of 2aminoethane phosphonic acid from rumen protozoa. Nature 184: $901 \sim 902,1959$

17) McQueney, M. S.; S. Lee, E. Bowman, P. S. Mariano \& D. Dunaway-Mariano: A remarkable pericyclic mechanism for enzyme-catalyzed P-C bond formation. $\mathrm{J}$. Amer. Chem. Soc. 111: 6885 6887, 1989

18) Nakashita, H.; A. Shimazu, T. HidaKa \& H. Seto: Purification and characterization of phosphoenolpyruvate phosphomutase from Pseudomonas gladioli B-1. J. Bacteriol. 174: 6857 6861, 1992

19) Seidel, H. M.; S. Freeman, H. Seto \& J. R. Knowles: Phosphonate biosynthesis: The isolation and characterization of phosphoenolpyruvate phosphomutase, the enzyme responsible for the formation of a carbon-phosphorus bond. Nature 335: 457 458, 1988

20) Bowman, E; M. McQueney, R. J. Barry \& D. Dunaway-Mariano: Catalysis and thermodynamics of the phosphoenolpyruvate/phosphonopyruvate rearrangement. Entry into the phosphonate class of naturally occurring organophosphorus compounds. J. Amer. Chem. Soc. 110: 5575 5576, 1988

21) Horiguchi, M. \& H. Rosenberg: Phosphonopyruvic acid: A probable precursor of phosphonic acids in cell-free preparation of Tetrahymena. Biochim. Biophys. Acta 404: $333 \sim 340,1975$

22) Imai, S.; H. Seto, T. Sasaki, T. Tsuruoka, H. Ogawa, A. Satoh, S. Inouye, T. Nidi \& N. Otake: Studies on the biosynthesis of bialaphos (SF-1293). 4. Production of phosphonic acid derivatives, 2-hydroxyethylphosphonic acid, hydroxymethylphosphonic acid and phosphonoformic acid by blocked mutants of Streptomyces hygroscopicus SF-1293 and their roles in the biosynthesis of bialaphos. J. Antibiotics 37: 1505 1508, 1984

23) Seto, H.; T. Hidaka, T. Kuzuyama, S. Shibahara, T. Usui, O. Sakanaka \& S. ImaI: Studies on the biosynthesis of fosfomycin. 2. Conversion of 2-hydroxypropylphosphonic acid to fosfomycin by blocked mutants of Streptomyces wedmorensis. J. Antibiotics 44: 1286 1288, 1991

24) Katayama, N.; S. Tsubotani, Y. Nozaki, S. HaRada \& H. ONO: Fosfadecin and fosfocytocin, new nucleotide antibiotics produced by bacteria. J. Antibiotics 43: $238 \sim 246,1990$

25) Cassaigne, A.; A. Lacoste \& E. Neuzil: Transamination non enzymatique des acides amines phosphoniques. Biochem. Biophys. Acta 252: 506 515, 1971 
26) Isbel, A. F.; L. F. Englert \& H. Rosenbery: Phosphonoacetaldehyde. J. Org. Chem. 34: 755 756, 1969

27) Nakashita, H. \& H. Seto: A new screening method for $\mathrm{C}-\mathrm{P}$ compound producing organisms by the use of phosphoenolpyruvate phosphomutase. Agric. Biol. Chem. 55: 2825 2829, 1991

28) Neale, A. D.; R. K. Scopes, R. E. H. Wettenhall \& N. J. HoogenRaAd: Pyruvate decarboxylase of Zymomonas mobilis: Isolation, properties, and genetic expression in Escherichia coli. J. Bacteriol. 169: 1024 1028, 1987

29) Zehender, H.; D. TRESChER \& J. UllRich: Improved purification of pyruvate decarboxylase from wheat germ. Eur. J. Biochem. 167: 149 154, 1987

30) Kuzuyama, T.; T. Hidaka, S. Imai \& H. Seto: Studies on the biosynthesis of fosfomycin. 4. The biosynthetic origin of the methyl group of fosfomycin. J. Antibiotics 45: $1812 \sim 1814,1992$ 